\title{
Parametric Modelling of Pedal Pressing Activities During Road Traffic Delay
}

\author{
Ahmad Niyzar Ahmad Zifruddin ${ }^{1, *}$, Salmiah Ahmad ${ }^{1}$, Hazril MD. Isa ${ }^{1}$, Muhammad \\ Abdullah ${ }^{1}$, Normaniha Abd Ghani ${ }^{2}$ and Nurul Muthmainnah Mohd Noor ${ }^{3}$ \\ ${ }^{1}$ Department of Mechanical Engineering, Kulliyyah of Engineering, International Islamic University Malaysia \\ ${ }^{2}$ Department of Electrical Engineering, College of Engineering, University Malaysia Pahang, Malaysia \\ ${ }^{3}$ School of Mechanical Engineering, Universiti Teknologi MARA, Pulau Pinang
}

\begin{abstract}
Traffic congestion in big cities in Malaysia has become a common scenario among the communities. The journey between homes to working place twice a day at considerable distances is no longer a strange situation. Being in traffic for hours in a sitting position requires recurrent tasks of manual pressing the pedal and brake excessively and if they are done without the correct sitting posture, it may trigger fatigue faster, particularly for the leg and back of the driver. In the long term, it will negatively affect the health of the driver, particularly in the form of physical, psychological, and emotional. Therefore, this paper is trying to investigate the recurrent brake pedal pressings as well as the leg postures while driving in traffic jam. The research is started with the experimental setup and data acquisition on brake pedal pressing as well as leg posture followed by the modelling and analysis of the obtained data using particle swarm optimization (PSO) modelling technique. The validation step was then executed to verify the model derived using open loop and closed loop performance analysis. The results show that the pedal pressing force of leg posture can be closely represented using $2^{\text {nd }}$ order transfer function and mimics the actual pedal pressing pattern during road traffic delay.
\end{abstract}

Keywords: Pedal pressing, PSO algorithm, Fatigue, Road traffic delay, Modelling, System identification, Braking system.

\section{INTRODUCTION}

The growth of a city is influenced by the city's topographical circumstances and transportation routes, according to urban planning theory, leading to significant traffic congestion, which is most noticeable at peak hours in the morning and evening, when people travel from home to work, school, or other events, and also when they return home. Traffic congestion may result in significant economic losses, longer travel times, and increased pollution. Governments spend a lot of money attempting to detect and analyse traffic congestion, but it appears that this is difficult due to the dynamic nature of traffic delays. Certain regulations, such as transportation planning, are necessary to ensure that the growth of the entire metropolitan region does not negatively impact the quality of life of individuals who live there.

Kuala Lumpur has experienced rapid growth and urbanisation in recent years, especially in terms of transport facilities and it is one of the busiest cities in Southeast Asia that has led to a huge increase in private car ownership. According to a BCG research, inhabitants of Kuala Lumpur spend an average of an hour each day stuck in traffic, [1]. KLites spend an

*Address correspondence to this author at Department of Mechanical Engineering, Kulliyyah of Engineering, International Islamic University Malaysia; Tel: +60364214506; E-mail: ahmadniyzar@gmail.com average of 2 weeks a year stuck in traffic, making it the sixth most congested area in Southeast Asia. Cars stuck in traffic appear to generate unneeded greenhouse gases, which may damage the atmosphere and have an influence on population health. The number of road accidents is anticipated to rise more as traffic density increases.

There are many studies has been done on particularly investigating the driver's sitting posture with fatigue and stress. Driving with the right posture is one of the most important aspects when driving a vehicle. Furthermore, it will effect on the driver's performance and health, long-term driving tiredness, also known as physical and mental exhaustion, and might impair a driver's performance, [2]. The effects of road and traffic conditions on mental tiredness are significant. Fatigue resulting from long-term driving can be classified into physical and mental fatigue, where physical fatigue seems to be mainly caused by driving posture. Numerous solutions for vehicle seats, such as altering back support position [3], have been created to decrease posture-induced fatigue. However, they are designed to refresh or slow down fatigue, not to eliminate the causes of fatigue.

The advantages of a proper driving position are clear, which are better visibility, better comfort and quicker response times [4-5]. In contract, an achy back, a stiff neck, a painful shoulder due to constant shaking, 
rattling, and rolling of everyday commuting will wear drivers out [6]. Some vehicle seats may not adequately fit the lower back curve, putting additional strain on the spine. According to a study conducted by [7], poorly positioned drivers are also at a higher risk of serious harm. The author further emphasized that in actual driving circumstances, drivers are frequently in a forward position due to improper driving postures, fatigue, or brake inertia.

Driving posture was utilised as reference data for the design of the driver's workspace's visibility, accessibility, and affordable clearance, [8]. Few studies have been reported that are useful to predicting the posture of vehicle passengers. [9] has examined the relationship between driving posture and seat design, while [10] have looked into the ideal range of joint angles (neck, shoulder, elbow, wrist, torso, spine, knee and ankle angles). Where the use of digital human models (DHM) to build a driving seat or assess a virtual environment has piqued the interest of researchers.

[11] objectively defined and identified the variables for seating techniques based on preferred driving postures. Three occupant kit (OPL) scenarios were simulated using motion capture technology, and the optimum driving positions for various body size drivers were determined. Their research also looked at how gender and OPL condition affected the suggested seating methods where forty drivers (twenty males and twenty females) in their twenties to fifties with more than two years of driving experience took part in the experiment. In the experiment, a changeable seat buck was built, and a motion capture equipment was employed. Under different OPL circumstances (coupe, sedan, and SUV), the seat buck may be adjusted by changing the seat, steering wheel, accelerator pedal, and brake position.

Because data in some early research were only supplied in aggregate or population distribution, the conclusions are not relevant to a general human model posture. According to [12] Who has reported that the most comprehensive technique to all-body driving posture prediction until today, the RAMSIS human model. It is a posture-data-gathering lab vehicle mockup used to the optimization-based method that he developed. They used data from a laboratory study of 68 men and women in vehicle and seat combinations spanning a broad range of passenger car interior geometry to develop a model for predicting automotive driver postures. The author has stated that the Cascade Prediction Model (CPM) prioritises precise prediction of hip and eye locations, which are two of the most important posture features for car interior evaluation. The position of the hip is strongly related to the position of the seat and lower extremities, whereas the position of the eye is critical for vision analysis. Furthermore, this method allows the CPM to be utilised with a variety of human figure model connections, as well as the basic components of the model that forecast hip and eye locations to be combined with additional ways to fit the torso and extremities. He emphasized that the regression functions generated from laboratory study findings predict hip and eye locations, which are the most important postural degrees of freedom for driver station ergonomics research. The original study found that seat height, steering wheel position, and seat cushion angle all had significant independent impacts on posture.

Yan et al. has investigated the characterization of driving postures using driver hand position using the Convolutional Neural Networks (CNN) architecture where the input of the system was used to create an internal representation of various driving postures, which is utilised to find the appropriate and accurate feature representations, [12]. The aim was to find out what kind of driving position the driver takes, which is discovered by following the raw input image to a high degree of detail. This research recommends the development of a deep CNN that automates the investigation of important data via the use of a trainable filter and a local community pooling method in alternative. Furthermore, their study focuses on determining driving postures based on where the driver's hand is placed. However, it is difficult to accurately estimate the hand area, because of the variety of light conditions and the limitations of skin region segmentation algorithms.

Xi et al. used an instrumented car in diverse driving activities to examine the pedal usage characteristics of elderly drivers. His study focuses on mistakes that occur when pedal input is applied, as well as older drivers' frequent occurrence in pedal input-related incidents [13]. Each driver's pedal travel (potentiometer), pedal force (Tekscan sensor), and foot motion were recorded by the instrumented car. When compared to their driving skills of the younger driver, older drivers are confronting a number of problems, such as impaired vision, slower reaction time, and limited movement range of their limbs. In the task to transfer the foot from the accelerator pedal to the brake pedal, participants had to move the foot from the accelerator pedal to the brake pedal, from the brake 
pedal to the accelerator pedal, from the floor to the brake pedal, and from the floor to the accelerator pedal. To replicate the recognised pedal-force/travel curve, two pedal-feel simulator designs was suggested, [15]. De Arruda Pereira, set out to discover how well connected the connections are between the pedal and pedal travel while evaluating four different Ford Fiesta rivals, [16]. He found a few key technical characteristics that determine pedal feel and utilised this information to determine pedal feel. This gave them the ability to figure out how the pedal feels because of the technical details and also provide a pedal design formula that is based on what a pedal could feel like after it's implemented. It was found that The best travel range for the brake pedal is $51 \mathrm{~mm}$ to $152 \mathrm{~mm}$, while the travel distance should be between $25 \mathrm{~mm}$ and $178 \mathrm{~mm}$ for drivers who wear boots, with the same optimum range as for normal shoes.

It has been well known that a critical aspect while operating a car is to maintain proper posture when driving. There is little doubt that greater vision, improved comfort, and quicker response times are all derived from good driving posture. Posture determines the structural or positional characteristics of the body, for example, the driver's seat, the steering wheel and the pedals [17]. Normally no ideal posture is thought to exist, and drivers can choose from a broad range of positions. These postural choices might be influenced by a variety of internal and external factors. Anthropometry, behaviour, and other personal qualities of the driver might be examples of internal or driverrelated factors. External factors such as weather, lighting, traffic, noise, and vibration are included as part of the driving environment, [18].

From the review made, it can be concluded that there are limited study made on the frequenly pressings of the brake and accelerator pedals on the fatigue and stress built up during road traffic delay. The modelling tachnique was not addressed in details especially in representing the actual data during road traffic delay. Thus, the purpose of this research is to identify the right pattern of pedal pressings during traffic road delays in order to decrease the causes of fatigue.

In this paper, we focused on modelling of the driver's pattern when pressing the brake pedal during traffic delay using system identification technique, due to driver's foot behaviour is a significant mean that has a direct effect on the vehicle control. The sensors that measure the pedal pressing force, pedal angle as well as leg angle were installed properly in the car. The findings of the proposed study is anticipated to assist the automobile industry in improving their abilities in creating technologies that can decrease driver's fatigue when stalled in traffic.

\section{EXPERIMENTAL DESIGN AND DATA ACQUISITION}

\subsection{Instrumentation and Measurement}

The experimental set up was designed accordingly in accommodating all related sensors and its circuits with signal conditioning. The experiment was set up properly in the car where the pedal pressings pattern and leg posture data were recorded using suitable sensors. The car we utilized for data collection was a four-door Perodua Axia 1.0 Standard G from Malaysia. The interiors of the car include an outstanding space inside a compact body, an interactive media frame with a strong connection $3+1$ seating arrangement offer more space to comfort and a lot more parameters, as shown below in Table 1. A flat sensor (load cell) was installed to measure the pedal pressing force, which the data was through Arduino and HX711 Load Amplifier Module, shown in Figure 1. MPU 6050 sensor was used to measure the angle of the pedal and the ankle angle and sent through Arduino Uno platform. The data from the Arduino application were collected and recorded for further analysis. The working principle behind a load cell is that there are four resistors laid out in a diamond pattern called a Wheatstone bridge, as shown in Figure 2. The circuit has two compression and tension resistor pairs. When weight is detected on the load cell, the compression and tension resistors will change their values in the opposite direction. If the current flows from top to bottom, then the output voltage between two remaining corners is measured. So when the force is applied through pedal pressing to the cell then the resistance values start to change and a voltage difference is measured. With a proper calibration, the force that is being applied to the cell can be calculated. The fact is that when no force is applied, all the resistor values are equal and the measurement voltage is zero. These are only half bridges, but actually we can combine them to form a full-bridge. The configuration shown in Figure 2 allows for exceptionally small fluctuations in the resistance that occurs in the strain gauges positioned in the bridge arms: $R 1, R 2, R 3$, and $R 4$. The circuit has been designed and constructed, as shown in Figure 3. On the other hand, Figure $\mathbf{4}$ shows the $\mathbf{5}$ connections from Arduino board to MPU 6050 Sensor. 
Table 1: Specifications, Perodua Axia 1.0 Standard G

\begin{tabular}{|l|l|}
\hline \multicolumn{1}{|c|}{ Specifications } & \multicolumn{1}{|c|}{ Value } \\
\hline \hline Overall length & $3645 \mathrm{~mm}$ \\
\hline Width & $1620 \mathrm{~mm}$ \\
\hline Height & $1510 \mathrm{~mm}$ \\
\hline Kerb weight & $850 \mathrm{~kg}$ \\
\hline $\begin{array}{l}\text { Min turning } \\
\text { radius (tyre) }\end{array}$ & $4.5 \mathrm{~m}$ \\
\hline Engine type & $\begin{array}{l}1 \mathrm{KR}-\mathrm{VE} \text {. DOHC, 12 V, Electronic Fuel } \\
\text { Injection (EFI), with VVT-I }\end{array}$ \\
\hline Safety \& security & $\begin{array}{l}\text { Dual SRS airbags, ABS with EBD, Anti-theft } \\
\text { device with alarm, immobilizer and panic } \\
\text { button, wireless door lock and alarm with } \\
\text { (key with integrated remote), Seat belt } \\
\text { reminder, Key reminder, Highlight reminder, } \\
\text { ISOFIX system }\end{array}$ \\
\hline
\end{tabular}

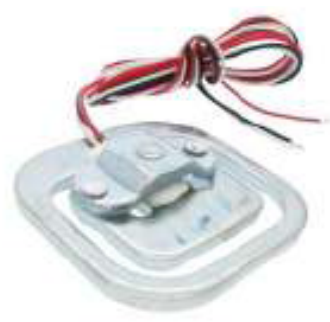

(a) Load Cell

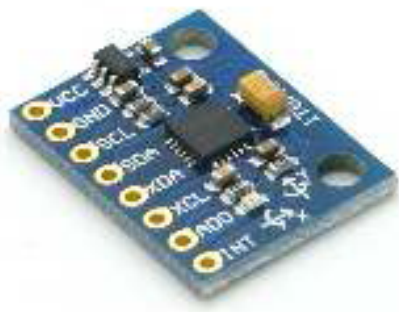

(b) MPU6050 Module
Figure 1: Sensors used for pedal force, pedal angle and ankle angle measurement.

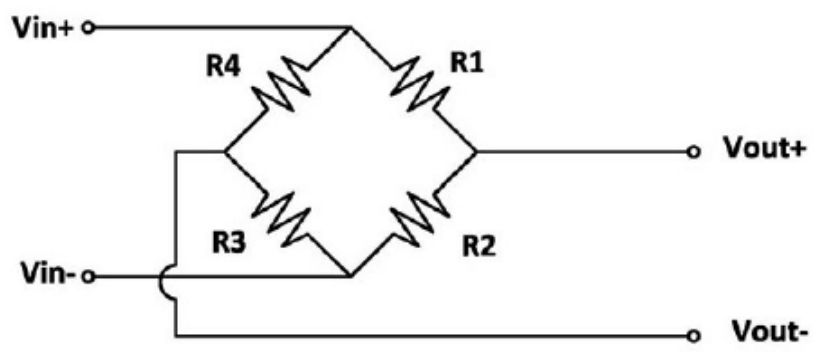

Figure 2: The Wheatstone bridge.

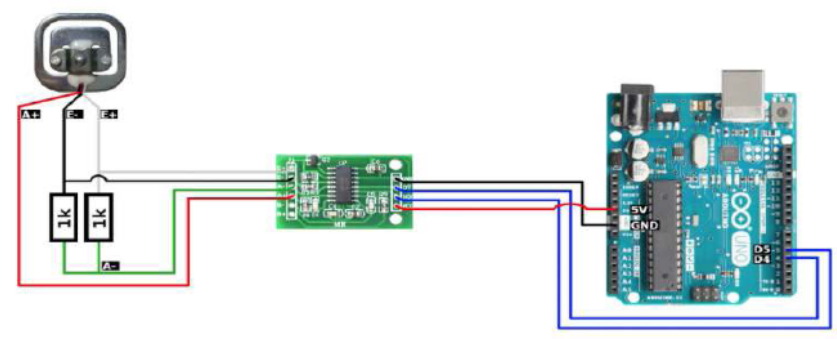

Figure 3: Load Cell Curcuit design and connection.

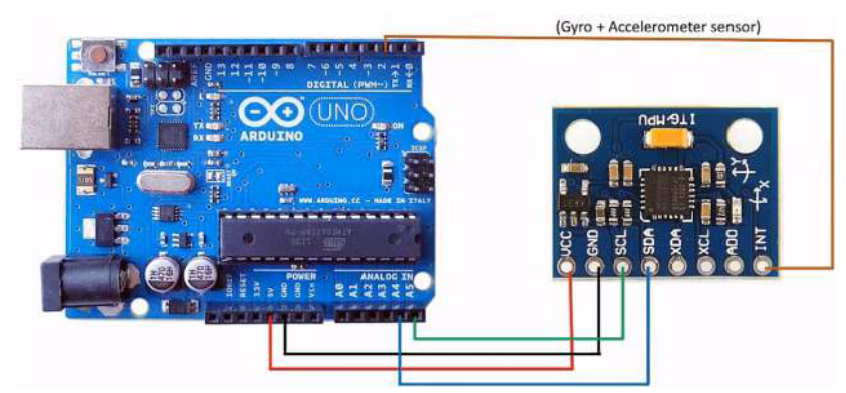

Figure 4: MPU6050 Circuit circuit design and connection.

The pedal pressing force, ankle angle, pedal angle and car speed have been acquired using all sensors that have been installed in the car, as shown in Figure 5. The data was collected using Arduino platform as their host to read the data from the sensors. Serial monitor in Arduino Application was used to see the data received from all input sensors and were connected to the Arduino through serial communication.

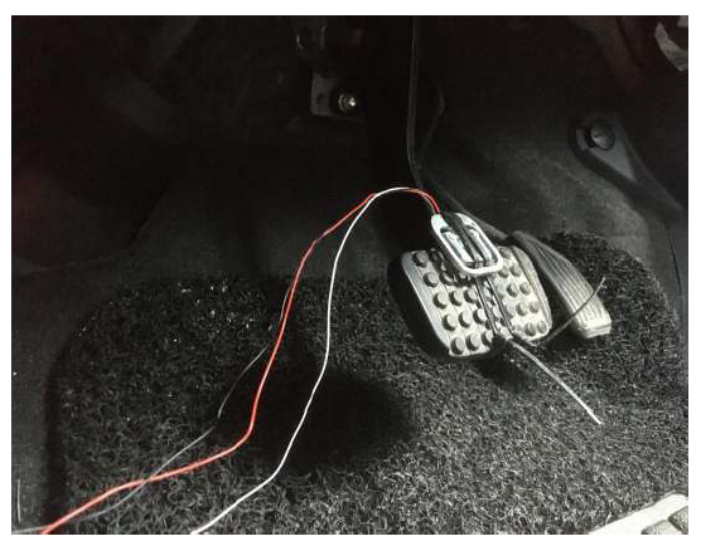

Figure 5: Load cell and brake pedal.

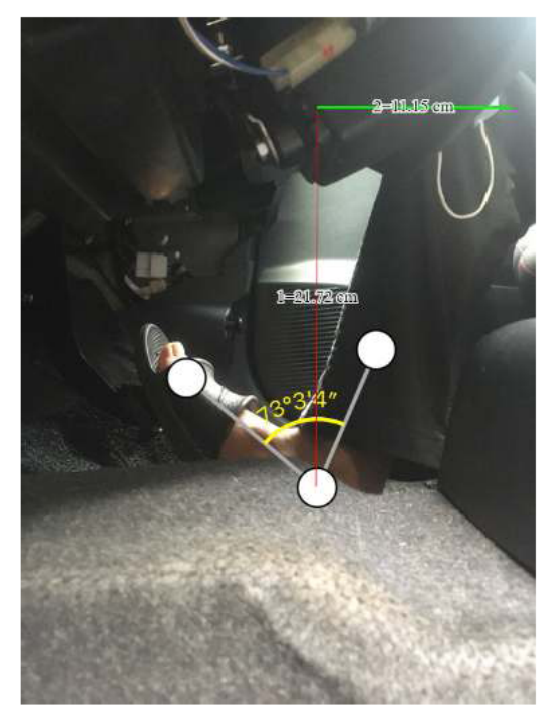

Figure 6: Ankle joint angle when brake pedal is released. 


\subsection{Data Collection and Analysis}

The angle of the joint ankle and the distance between ankle and knee is measured, as described in Figure 6, where it shows the ankle joint when the driver releases his foot from the brake pedal and Figure 7 shows the ankle joint angle when driver presses the brake pedal.

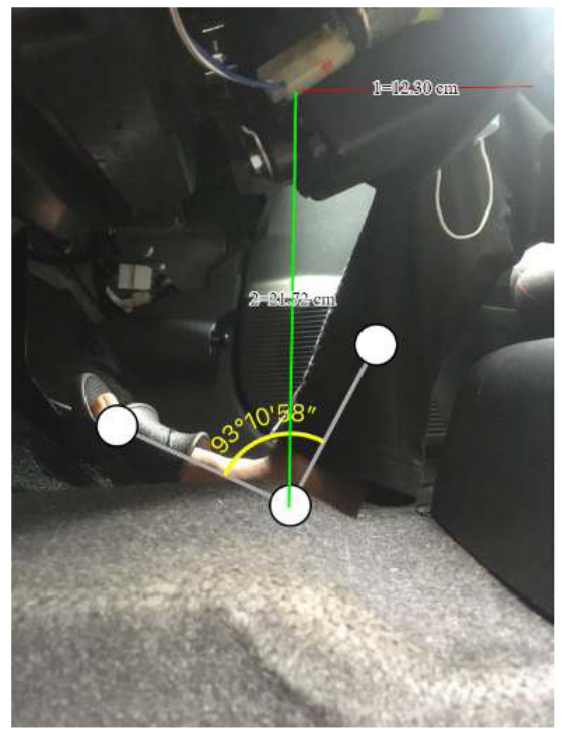

Figure 7: Ankle joint angle when brake pedal is pressed.
The experiment was conducted in Bandar Kemaman, Terengganu as the road delay was mimicked around several roads in Bandar Kemaman. The experiment conducted has took about 17 minutes to complete driving around Bandar Kemaman. Figure 8 shows the graph of the driver when he pressed down and release the brake pedal for around 17 minutes during road traffic delay. It indicates that when he pressed down the brake pedal, the force that is detected by the sensor will be higher. It also shows that the driver has pressed the brake 7 times for an average of 5 minutes and 21 times for 17 minutes of the experiment. The ankle joint angle indicates that when the driver pressed the brake pedal, the angle of the joint ankle is greater than $90^{\circ}$ and with the maximum of $140^{\circ}$. When the driver releases the brake pedal, the ankle joint angle is less than $90^{\circ}$ but greater than $70^{\circ}$. The distance between the ankle and knee when the driver pressed the brake pedal is $12.30 \mathrm{~cm}$, and 11.15 $\mathrm{cm}$ when the driver released the brake pedal. Figure 9 depicts the graph of pedal angle when the brake pedal was pushed and released. When the driver presses the brake pedal, the angle of the pedal decreases, and when the driver releases the brake pedal, the angle of the pedal increases. Figure 10 shows the graph of

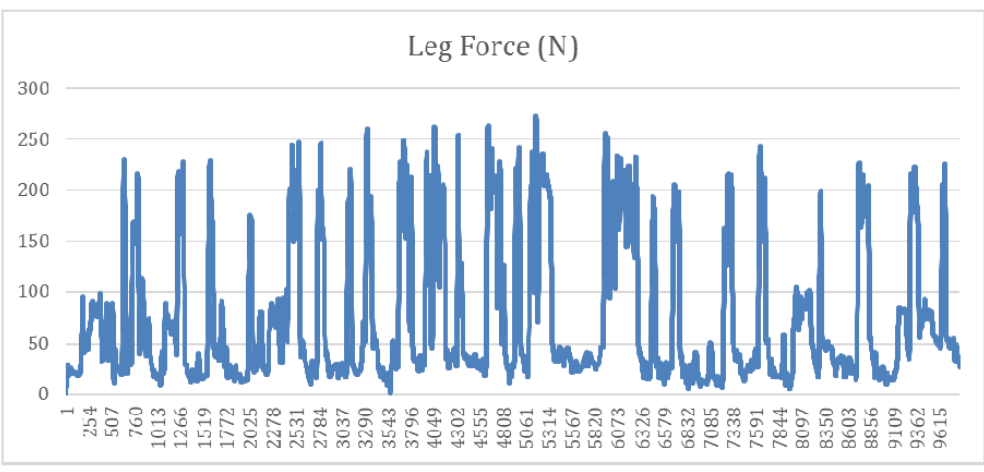

Figure 8: Pedal force $(\mathrm{N})$ versus time (seconds) graph representation.

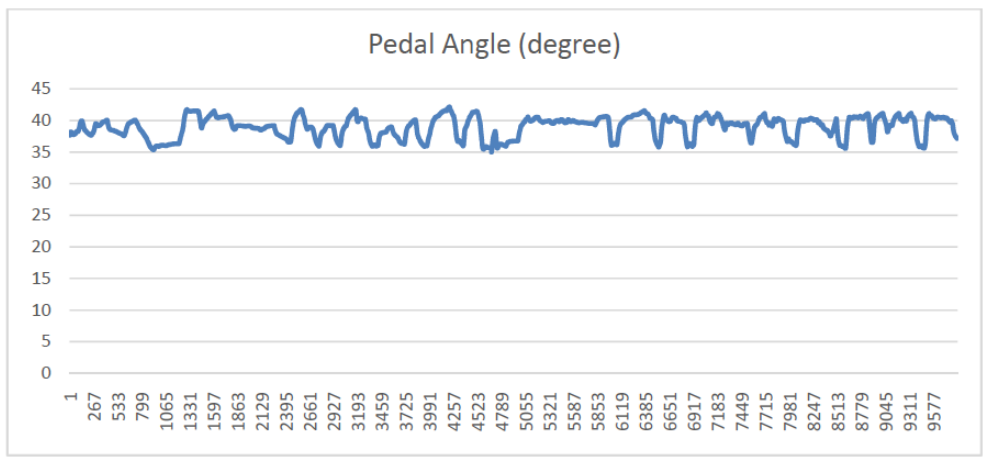

Figure 9: Pedal Angle $\left({ }^{\circ}\right)$ versus time (seconds). 


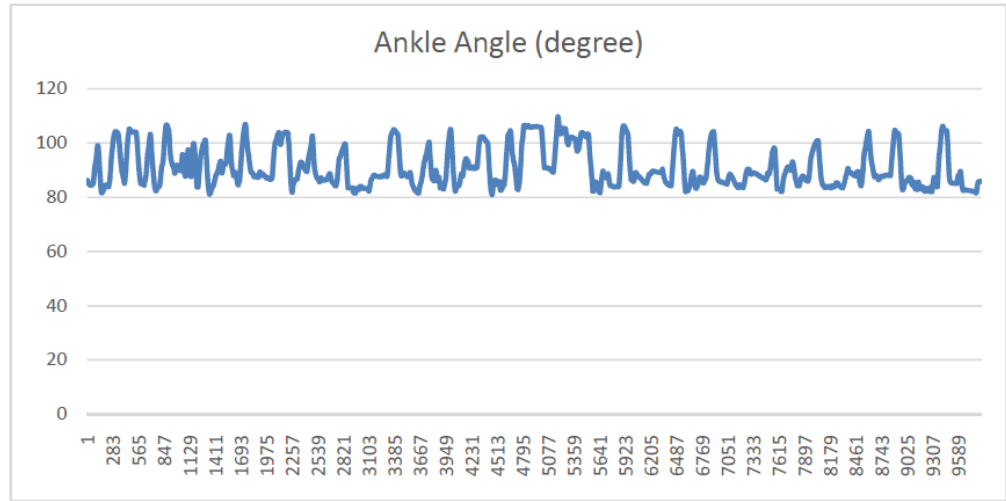

Figure 10: Ankle angle $\left({ }^{\circ}\right)$ versus time (seconds).

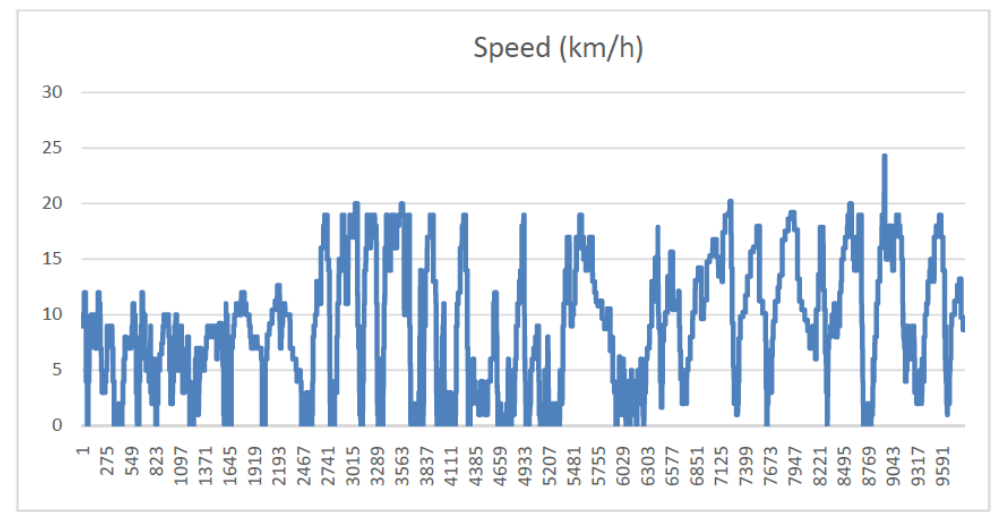

Figure 11: Output Speed of the car $(\mathrm{km} / \mathrm{h})$.

ankle angle when the driver flexes and extends the ankle. The ankle angle will decrease when the driver flexes his ankle and when he extends his ankle, the angle of the pedal will increase. While the speed of the car can be seen in Figure 11.

\section{PARAMETRIC MODELLING USING PARTICLE SWARM OPTIMIZATION ALGORITHM (PSO)}

Particle swarm optimisation (PSO) is an optimization technique based on evolutinary algorithm. The algorithm searches for global solution by utilizing a number of particles that cooperate with each other [18]. Like any other optimization method, PSO has been widely used in optimizing parameters that maps the relationthip between two variables, due to it is much simpler and able to converge towards global solution in shorter time.

Generally, the algorithm starts with a number of candidate solutions, called particles, spread over a large area called function. Each and every single particle is placed randomly around the function, in which the distance of each particle with optimal solution is recorded.

As the iteration progresses, the position and velocity of each particle is updated so that they are closer towards the solution. A fitness function is utilized in each iteration to evaluate the position of each particle.

In parametric modeling, each particle is considered as a candidate solution for optimal value of transfer function coefficient. Hence, in this study, the parametric modeling method used is PSO, combined with Spread Factor Algorithm as it proved to be effective and able to counter the drawbacks of PSO [19-20].

\section{PARAMETRIC MODELLING USING PSO}

\subsection{Force (Input) and Pedal Angle (Output)}

Figure 12 illustrates the dynamic SFPSO provided squared error (MSE) value based on the objective function assigned. 


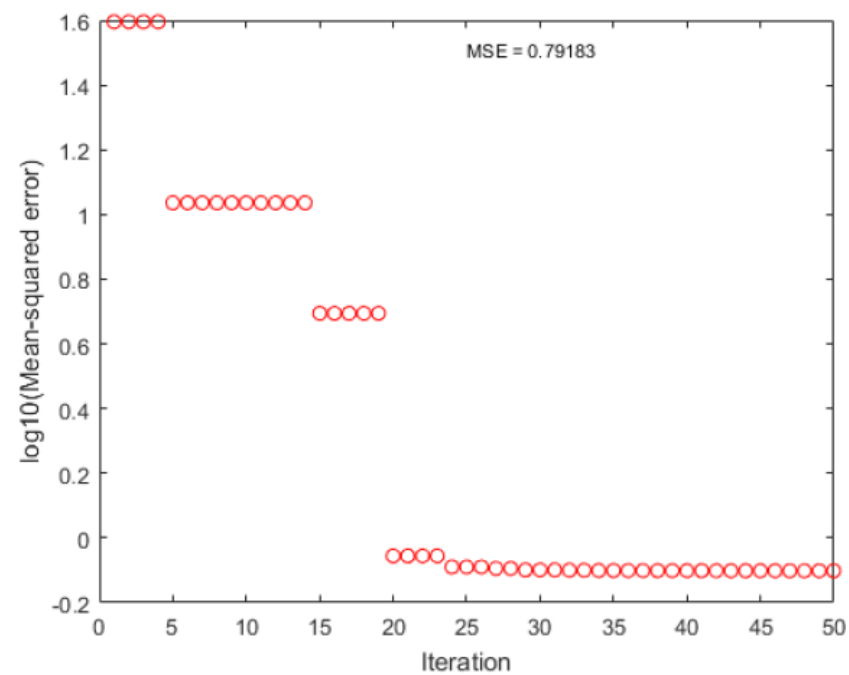

Figure 12: Convergence of SFPSO.

The MATLAB function was used to convert this discrete transfer function to its corresponding continuous form in the s-domain.

$$
H(s)=\frac{0.01312 s+0.001111}{s^{2}+0.08512 s+0.002181}
$$

Figure 13 shows that the expected output closely tracks the actual output in the time domain. As illustrated in the pole-zero figure, all the poles are inside the unit circle, while some of the zeros are outside, see Figure 14. This indicates that the model is stable and does not have a minimum phase. The predicted and actual outputs are displayed in the frequency domain shown in Figure 15 to demonstrate that the model correctly captured the system dynamics surrounding the primary resonance mode, reaching an MSE of 0.79183 . The correlation validation of the vertical plane motion model is visualized in Figure 16.

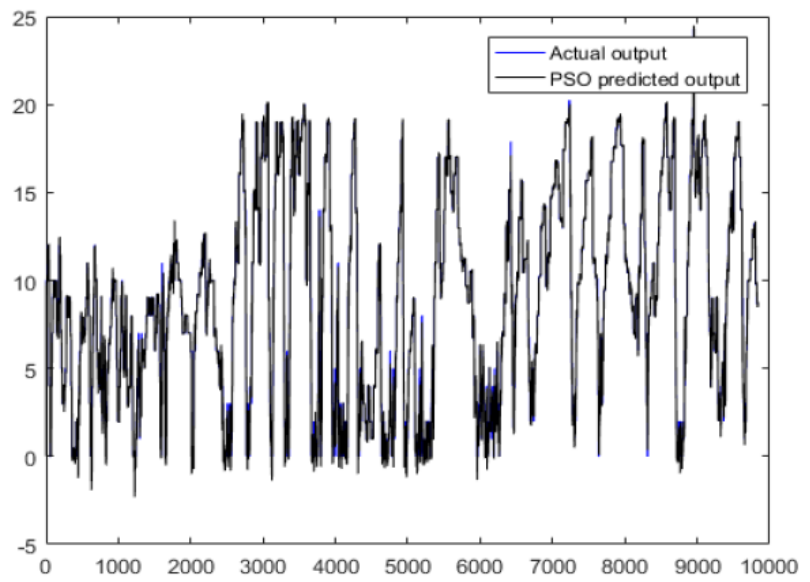

Figure 13: Actual and PSO predicted output.

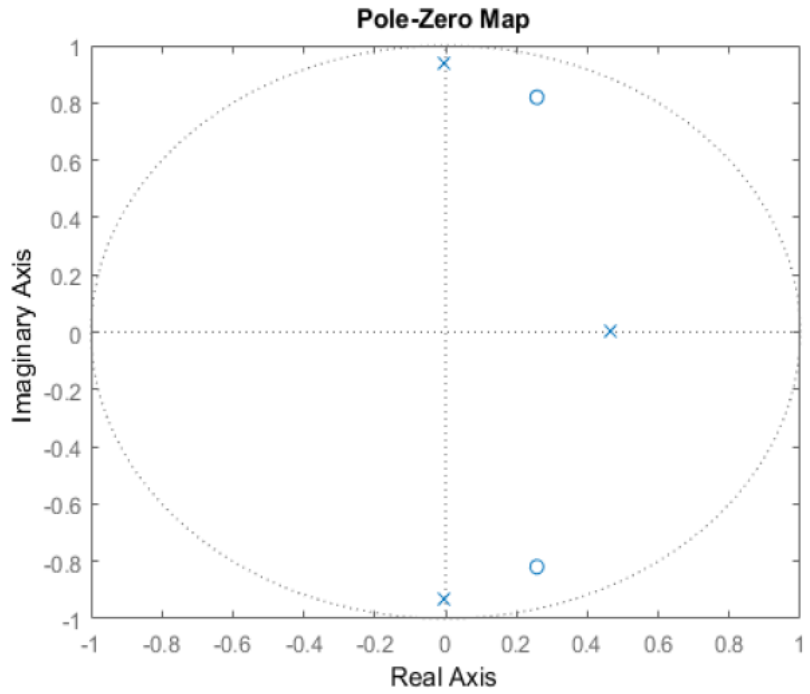

Figure 14: Pole-zero diagram.

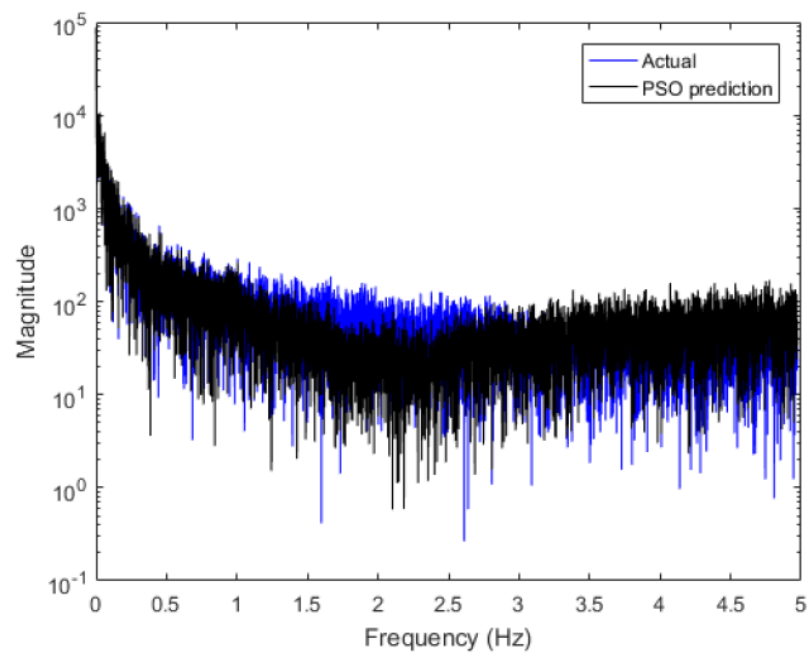

Figure 15: Actual and dynamic SFPSO projected output power spectral density.

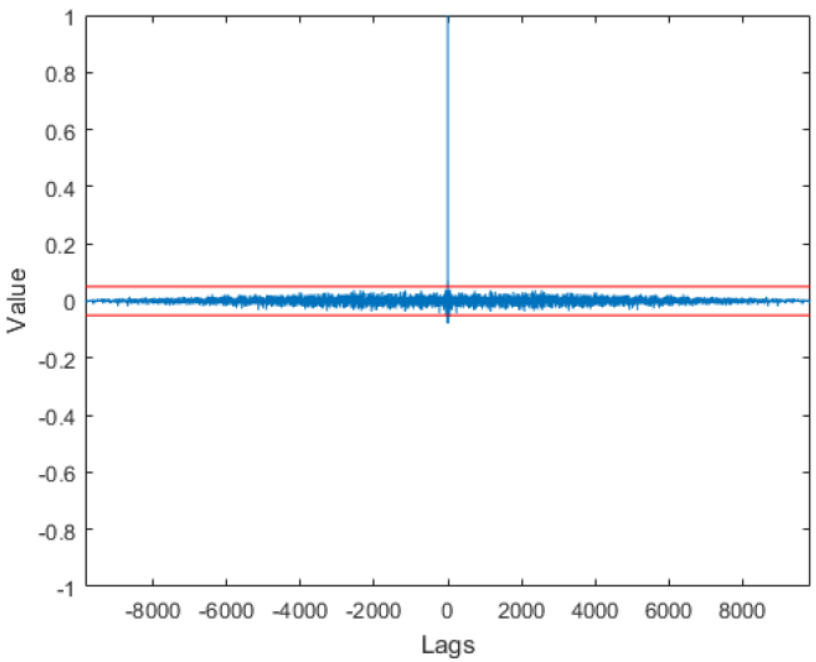

Figure 16: Correlation validation test. 


\subsection{Force (Input) and Vehicle Speed (output)}

Figure 17 illustrates that the dynamic SFPSO provided Mean Squared error (MSE) value based on the objective function assigned.

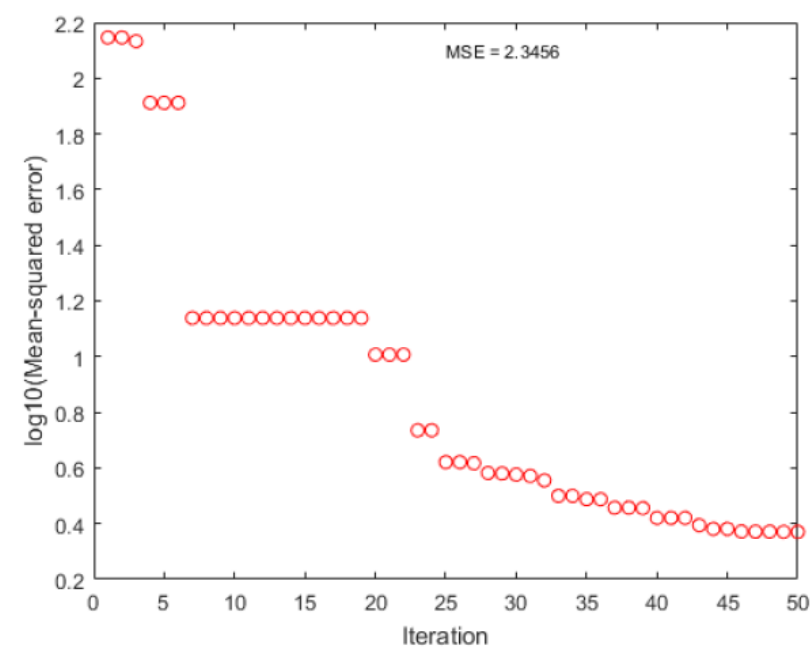

Figure 17: Convergence of SFPSO

The MATLAB function was used to convert the discrete transfer function to itscorresponding continuous form in the s-domain.

$$
H(s)=\frac{0.23533 s+0.0006884}{s^{2}+4.054 s+0.0005812}
$$

Figure 18 shows that the expected output closely tracks the actual output in the timedomain.

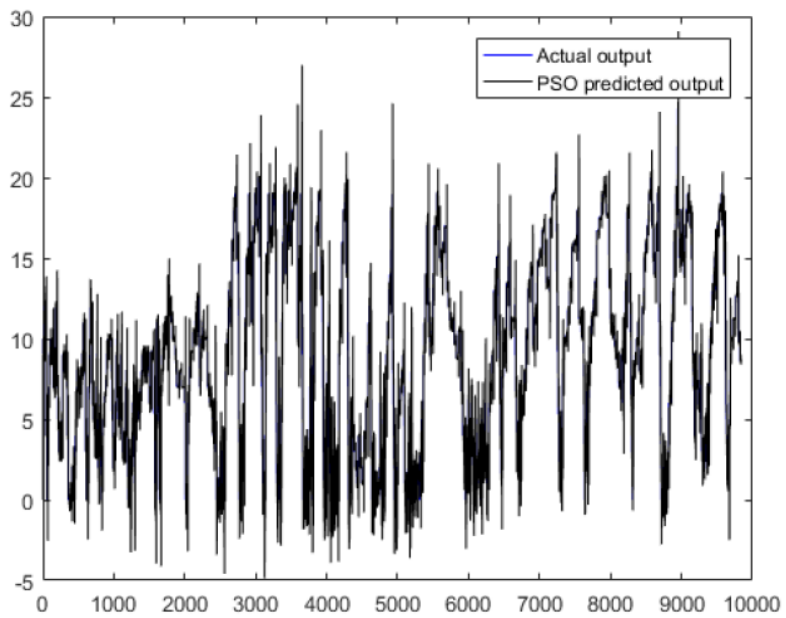

Figure 18: Actual and PSO predicted output.

As illustrated in the pole-zero figure, all the poles are inside the unit circle, while some of the zeros are outside, shown in Figure 19. This indicates that the model is stable and does have a minimum phase.

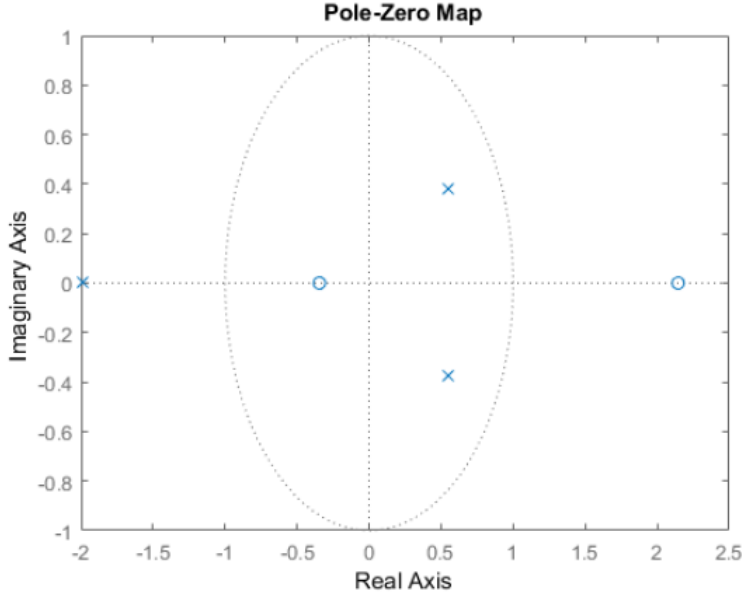

Figure 19: Pole-zero diagram.

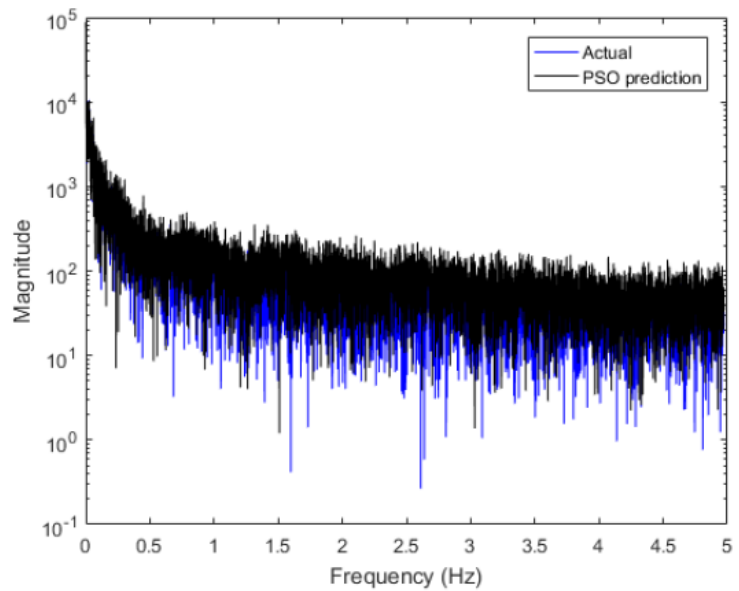

Figure 20: Actual and dynamic SFPSO projected output power spectral density.

The predicted and actual outputs are displayed in the frequency domain shown in Figure 20 to demonstrate that the model correctly captured the system dynamics surrounding the primary resonance mode. The dynamic SFPSO has reached an MSE of 2.3456

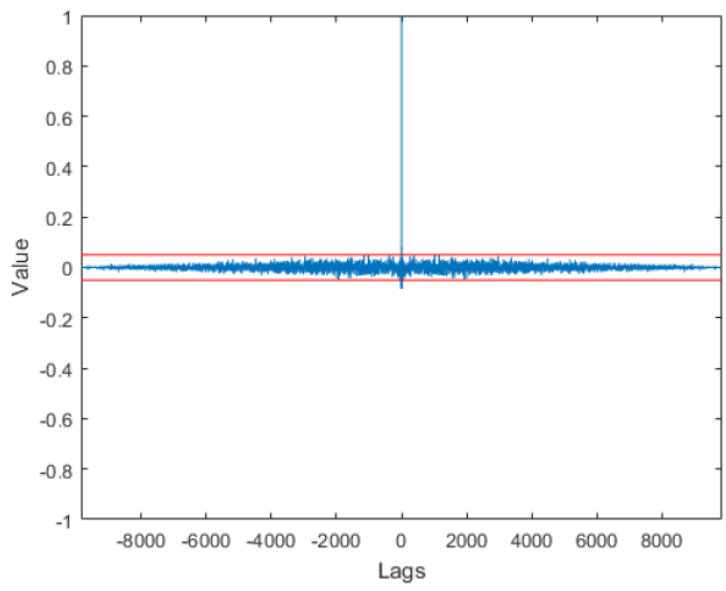

Figure 21: Correlation validation test. 
The correlation validation of the vertical plane motion model is visualized in Figure 21.

\subsection{Pedal Angle (input) and Vehicle Speed (output)}

Figure 22 illustrates the dynamic PSO provided an acceptable Mean squared error (MSE) value based on the objective function assigned.

The MATLAB function was used to convert this discrete transfer function to its corresponding continuous form in the s-domain. Then the transfer function is:

$$
\mathrm{H}(\mathrm{s})=\frac{-0.01451 s+0.03283}{s^{2}+0.124 s+0.1442}
$$

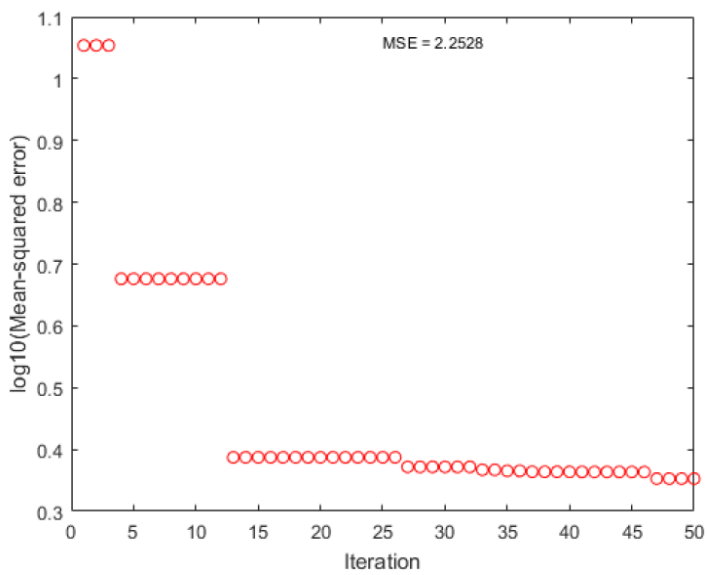

Figure 22: Convergence of local PSO.

Figure 23 shows that the expected output closely tracks the actual output in the time domain.

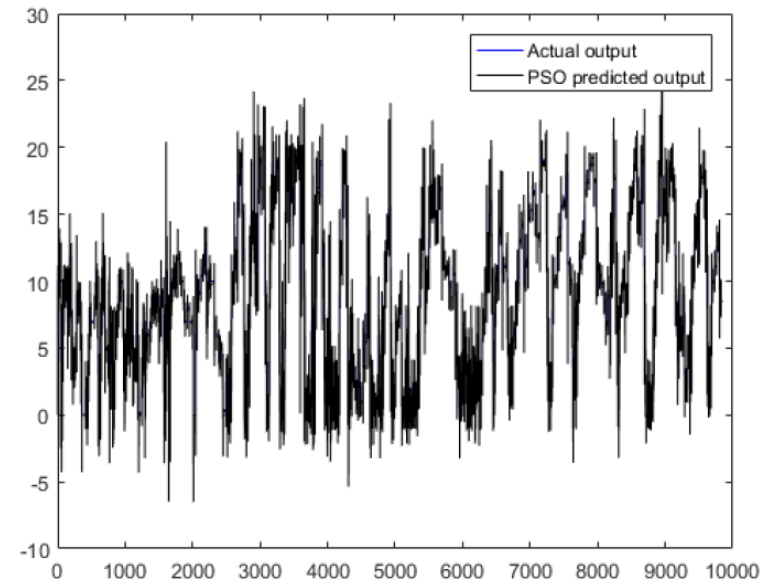

Figure 23: Actual and PSO predicted output.

As illustrated in the pole-zero figure, all the poles are inside the unit circle, while some of the zeros are outside, a seen in Figure 24. This indicates that the model is stable and does have a minimum phase.

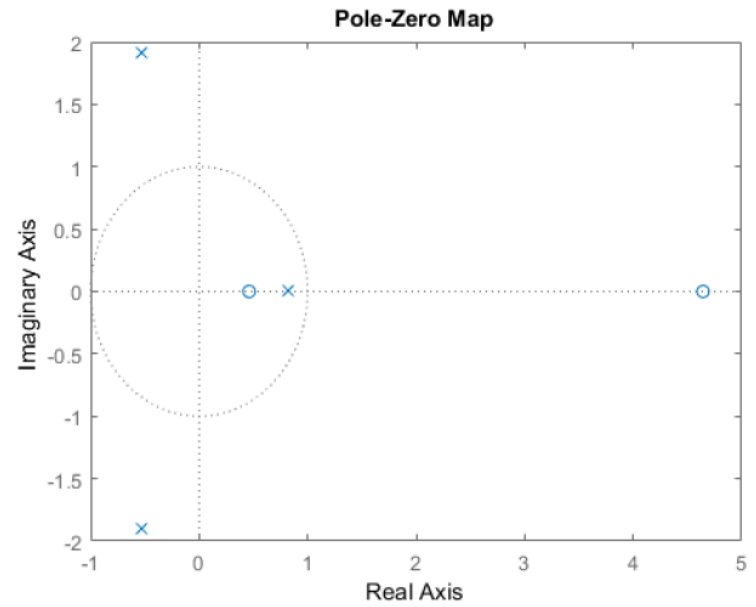

Figure 24: Pole-zero diagram.

The predicted and actual outputs are displayed in the frequency domain, shown in Figure 25, to demonstrate that the model correctly captured the system dynamics surrounding the primary resonance mode. The SFPSO has reached an MSE of 2.2528, while the correlation validation of the vertical plane motion model can be visualized in Figure 26.

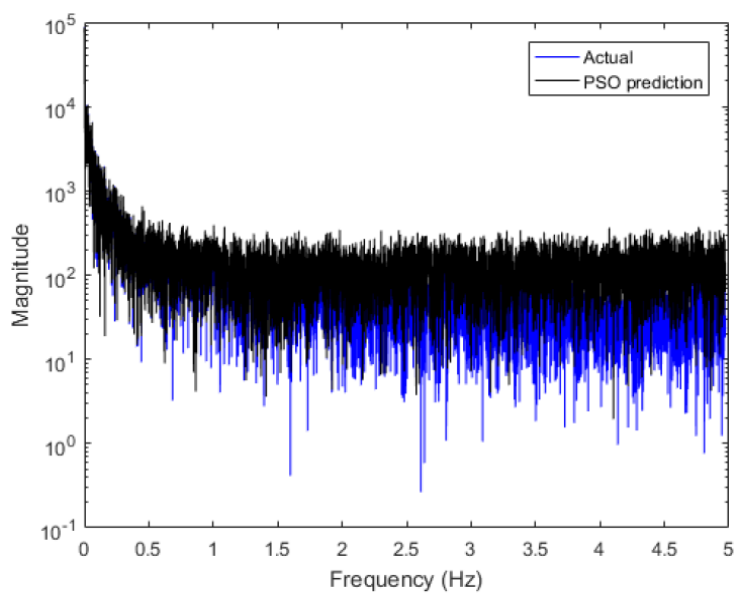

Figure 25: Actual and dynamic PSO projected output power spectral density.

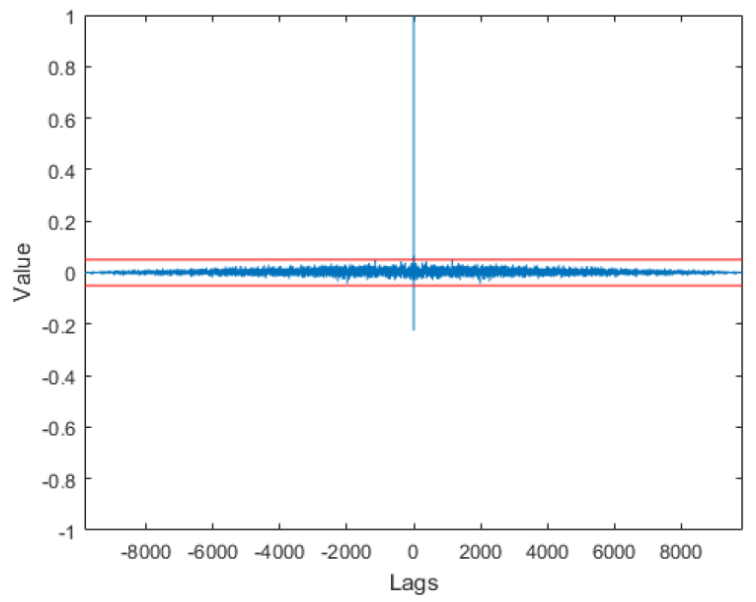

Figure 26: Correlation validation test. 


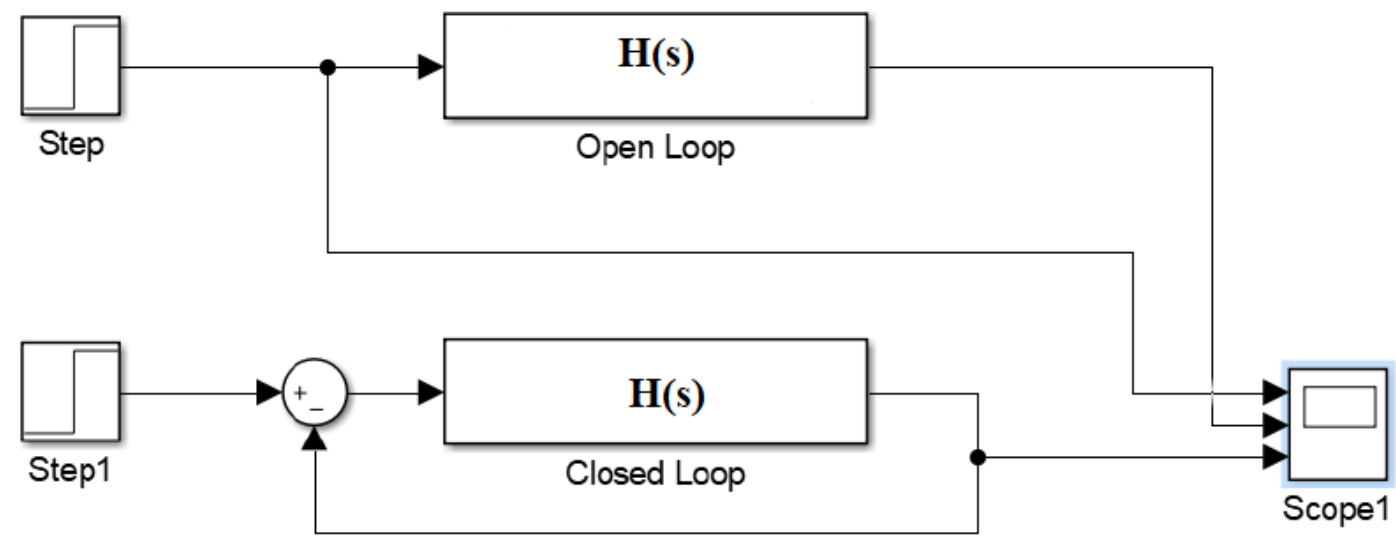

Figure 27: Open Loop and Closed Loop Block Diagram for validation.

\section{MODEL VALIDATION}

\subsection{Model Validation of Pedal Angle $\left({ }^{\circ}\right)$ vs Force (N)}

For the validation of the data, Simulink application in MATLAB has been used to find the output with the given input to the system. Open loop and closed loop system have been setup in Simulink platform, as shown in Figure 27.

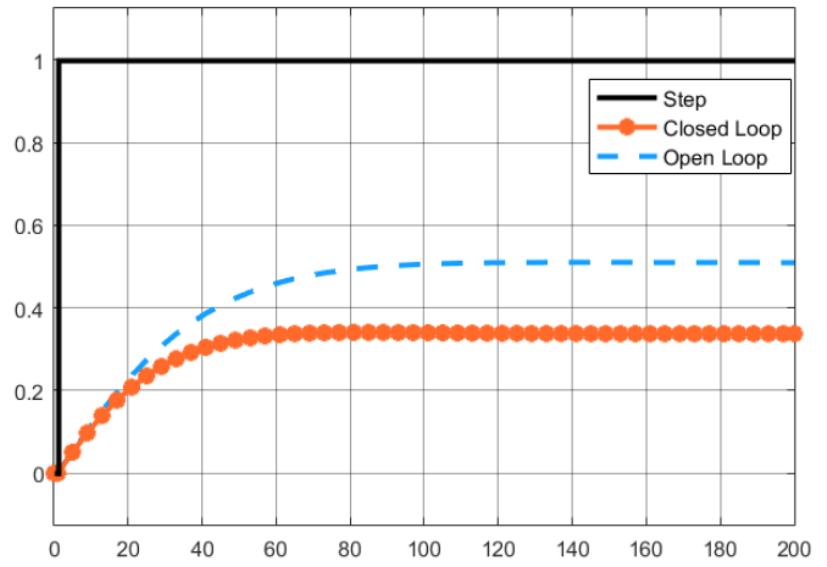

Figure 28: Validated pedal angle $\left({ }^{\circ}\right)$ response with force $(\mathrm{N})$ input for both open loop and closed loop systems.

After getting the model of the system in transfer function, the model is being validated using Simulink application in MATLAB. Figure 28 shows the pedal angle response $\left({ }^{\circ}\right)$ graphs both for open loop and closed loop. It can be seen that the model works logically based on the expected performance without any controller.

\subsection{Model Validation of Speed ( $\mathrm{km} / \mathrm{h})$ vs Force (N)}

Figure 29 shows the open loop and the closed loop graphs of the speed $(\mathrm{km} / \mathrm{h})$ response.

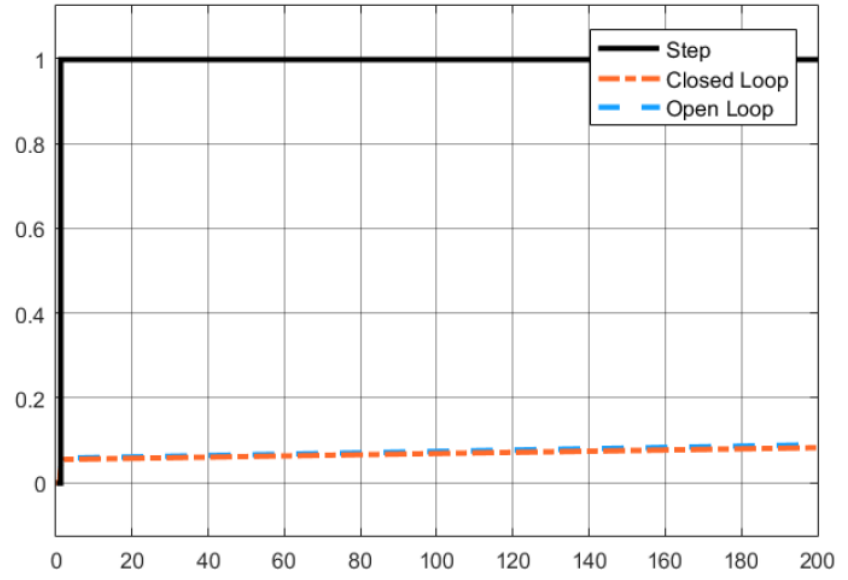

Figure 29: Validated speed response with force $(\mathrm{N})$ input for both open loop and closed loop systems.

\subsection{Model Validation of Speed $(\mathrm{km} / \mathrm{h})$ vs Pedal Angle $\left({ }^{\circ}\right)$}

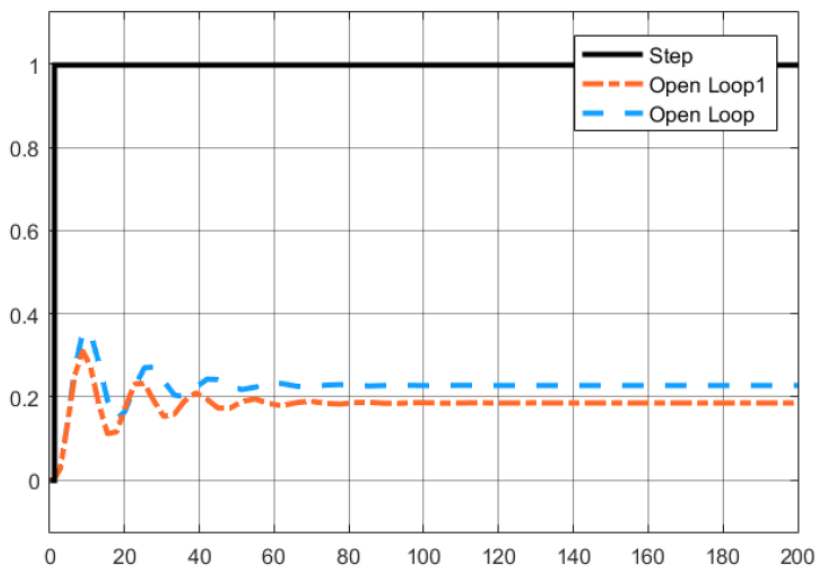

Figure 30: Validated speed response $(\mathrm{km} / \mathrm{h})$ with pedal angle $\left({ }^{\circ}\right)$ input for both open loop and closed loop systems. 
Figure 30 shows the speed response $(\mathrm{km} / \mathrm{h})$ with pedal angle $\left({ }^{\circ}\right)$ for both open loop and closed loop system.

\section{CONCLUSION}

The proper experiments that consists of instrumentation and measurement of related sensors have been fully conducted to acquire data of the pedal pressing force, the pedal angle and the ankle angle. The Particle Swarm Optimization PSO technique with Spread Factor has been successfully utilized in representing the parametric tranfser function of the systems. The transfer functions obtained have been validated using open loop and closed loop analysis and the model has functioned logically as expected. Therefore, in future work, this experiment can be executed properly in the heavy city like Kuala Lumpur and to explore the problem, more trials on longer stretches of road and greater platoon sizes need to be carried out.

\section{ACKNOWLEDGMENT}

The authors would like to acknowlegde the sponsor of the grant, IIUM-UMP-UITM Sustainable Research Collaboration Grant 2020 (SRCG), SRCG20-015-0015 (Modelling And Analysis Of An Automatic Mechanism For Recurrent Pedals Pressings During Road Traffic Delay) and The Ministry of Higher Education Malaysia under FRGS/1/2021/TK0/UIAM/02/27S (The Effect of Recurrent Pedal Pressings and Sitting Posture on the Driver's Fatigue During Road Traffic Delay via System Identification Models and Deep Learning Techniques).

\section{REFERENCES}

[1] Fun P. (2017, December 03). KL-ites Spend 53 Minutes Stuck in Traffic Jams Every day, Study Shows. Retrieved June 25, 2021, from https://worldofbuzz.com/kl-ites-spend53-minutes-stuck-traffic-jams-everyday-study-shows/.

[2] Hirao, Akinari \& Kato, Kazuhito \& Kitazaki, Satoshi \& Yamazaki, Nobutoshi. (2007). Evaluations of Physical Fatigue during Long-term Driving with a New Driving Posture. SAE Technical Papers. https://doi.org/10.4271/2007-01-0348

[3] Yamakawa et al. (2020). A Study On Fatigue Reduction Of Driver By Changing Back Support Position During Long Time Driving. Journal of Physics: Conference Series. 1532(1), IoP Publishing. https://doi.org/10.1088/1742-6596/1532/1/012025

[4] Lantoine et al. Car Seat Impact on Driver's Sitting BehaviourAnd Perceived Discomfort During Prolonged Real Driving On varied Road Types. PLoS One 2021; 16(11). https://doi.org/10.1371/journal.pone.0259934

[5] Yusoff ISM, Tamrin SBM, \& Majid AZA. (2021). Elderly Taxi Drivers: Evaluation Of Driving Posture In Malaysia Using
Rapid Upper Limb Assessment (RULA) Approach. Convergence of Ergonomics And Design: Proceedings of ACED SEANES 2020, 1298, 308. https://doi.org/10.1007/978-3-030-63335-6 32

Gyulyev et al. (2019). Modeling The Effect of Traffic Jam On Diver's Level of Fatigue. SHS Web Of Conferences. https://doi.org/10.1051/shsconf/20196704005

Luo X, Du W, Xu S, Yang J, \& Zhang J. Effects of a Forward Displaced Position on Driver Injury Levels in Frontal Crashes. Proceedings of the 2015 International Conference on Advanced Engineering Materials and Technology 2015. https://doi.org/10.2991/icaemt-15.2015.90

[8] Andreoni G, Santambrogio GC, Rabuffetti M, \& Pedotti A Method for the analysis of posture and interface pressure of car drivers. Applied Ergonomics 2002; 33(6): 511-522. https://doi.org/10.1016/S0003-6870(02)00069-8

[9] Park J, Choi Y, Lee B, Jung K, Sah S, \& You H. A Classification of Sitting Strategies based on Driving Posture Analysis. Journal of the Ergonomics Society of Korea 2014; 33(2): 87-96.

https://doi.org/10.5143/JESK.2014.33.2.87

[10] Kyung, Gyouhyung \& Nussbaum, Maury. Specifying comfortable driving postures for ergonomic design and evaluation of the driver workspace using digital human models. Ergonomics 2009; 52: 939-53. https://doi.org/10.1080/00140130902763552

[11] Reed MP, Manary MA, Flannagan CA, \& Schneider LW. A Statistical Method for Predicting Automobile Driving Posture. Human Factors: The Journal of the Human Factors and Ergonomics Society 2002; 44(4): 557-568. https://doi.org/10.1518/0018720024496917

[12] Yan C, Coenen F \& Zhang B. Driving posture recognition by convolutional neural networks. IET Computer Vision 2016; 10(2): 103-114.

https://doi.org/10.1049/iet-cvi.2015.0175

[13] Xi Y, Brooks J, Venhovens P, Rosopa P, Desjardins J Mcconomy S, Staplin L. Understanding the Automotive Pedal Usage and Foot Movement Characteristics of Older Drivers. SAE Technical Paper Series 2018; 04 https://doi.org/10.4271/2018-01-0495

[14] Zehnder JW, Kanetkar SS, \& Osterday CA. Variable Rate Pedal Feel Emulator Designs for a Brake-By-Wire System. SAE Technical Paper Series 1999; 03. https://doi.org/10.4271/1999-01-0481

[15] Dairou V, Priez A, Sieffermann J, \& Danzart M. An Original Method to Predict Brake Feel: A Combination of Design of Experiments and Sensory Science. SAE Technical Paper Series 2003; 03. https://doi.org/10.4271/2003-01-0598

[16] Freier S, Seeley P, Marklin R, \& Saginus K. Application of electric utility workers' anthropometry to clearance between vehicle pedals and adjacent structures. Psyc EXTRA Dataset 2010.

https://doi.org/10.1037/e578762012-006

[17] Fatollahzadeh K. (2006). A laboratory vehicle mock-up research work on truck driver's seat position and posture: $A$ mathematical model approach with respect to anthropometry, body landmark locations and discomfort. Doctoral Thesis, Royal Institute of Technology Division of Industrial Ergonomics, available at https://www.divaportal.org/smash/get/diva2:10461/FULLTEXT01.pdf.

[18] Kennedy J, \& Eberhart R. Particle swarm optimization. Proceedings of ICNN'95 - International Conference on Neura Networks 1995

[19] Toha S, Latiff IA, Mohamad M, \& Tokhi M. Parametric Modelling of a TRMS Using Dynamic Spread Factor Particle Swarm Optimisation. 2009 11th International Conference on Computer Modelling and Simulation 2009. https://doi.org/10.1109/UKSIM.2009.109 
[20] Wang D, Tan D, \& Liu L. Particle swarm optimization algorithm: An overview. Soft Computing 2017, 01; 22(2):

https://doi.org/10.1007/s00500-016-2474-6 387-408.

Received on 01-11-2021

Accepted on 05-01-2022

Published on 26-01-2022

DOI: https://doi.org/10.31875/2409-9848.2022.09.1

(c) 2022 Zifruddin et al.; Zeal Press.

This is an open access article licensed under the terms of the Creative Commons Attribution Non-Commercial License

(http://creativecommons.org/licenses/by-nc/4.0/), which permits unrestricted, non-commercial use, distribution and reproduction in any medium, provided the work is properly cited. 